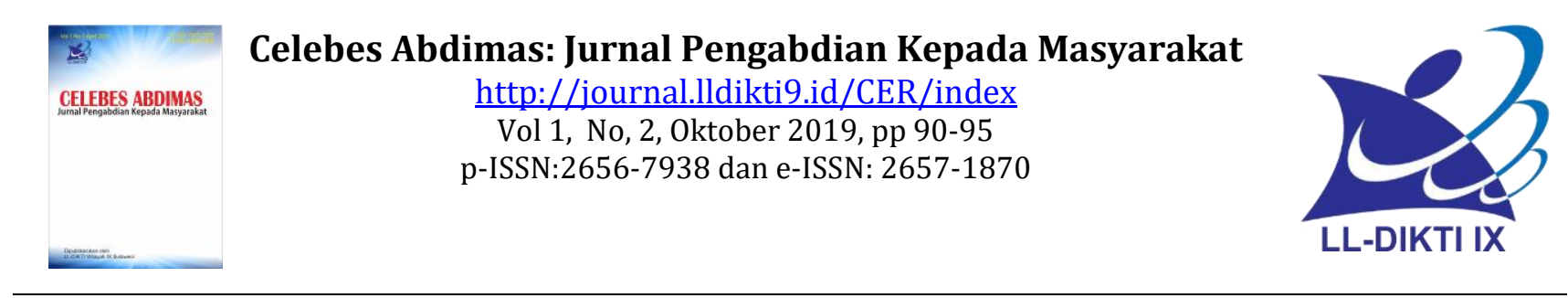

\title{
Penyuluhan Kesehatan Tentang Kesehatan Jiwa Usia Muda (Remaja) Pendekatan Keluarga Dan Agama Sebagai Preventif Psychosocial Trauma
}

\author{
Tutur Kardiatun' ${ }^{1}$, Wida Kuswida Bhakti ${ }^{2}$, Ramadhaniyati ${ }^{3}$, Sri Ariyanti ${ }^{4}$, Tri Wahyuni ${ }^{5}$ \\ ${ }^{1}$ Ilmu Keperawatan, STIK Muhammadiyah Pontianak \\ Email: ajeng_ners@yahoo.com \\ 2 Ilmu Keperawatan, STIK Muhammadiyah Pontianak \\ Email: wida.kuswida@gmail.com \\ 3 Ilmu Keperawatan, STIK Muhammadiyah Pontianak \\ Email:niyanaura@gmail.com \\ 4 Ilmu Keperawatan, STIK Muhammadiyah Pontianak \\ Email: sriariyantiskepners@yahoo.co.id \\ 5 Ilmu Keperawatan, STIK Muhammadiyah Pontianak \\ Email: fandisofyan@rocketmail.com
}

\section{Artikel info}

\section{Artikel history:}

Received;Agustus-2019

Revised: September-2019

Accepted;Oktober-2019

Publish: Oktober-2019
Abstract. The general objective of community service with Health Education on Young Mental Health (Adolescents) this Family and Religion approach as Psychosocial Trauma is to increase promotive efforts to stimulate the creation of mental health for young people (adolesencents) in LPKA class IIB Sungai Raya by optimizing the role of the family and religious base, is expected to be able to form characteristics of adolesecents who always have strong religious beliefs in thinking and acting, positive thinking, actualizing themselves well, and having a better outlook on life. The PKM method is to use lecture and discussion techniques. The target of this activity is young people (adolesencents) who inhabit LPKA class IIB Sungai Raya Pontianak Regency. The PKM implementing team is a lecturer involving, educational staff and students of the STIK Muhammadiyah Pontianak. The results of the implementation of the PKM showed the enthusiasm of active participants because the theme of health was never known by students in the LPKA class IIB Sungai Raya and the activities took place in an orderly manner. Of the 25 health participants, $80 \%$ of participants were able to answer correctly from the 5 questions given during the summative evaluation. an increase in knowledge of the participants about mental health.

Abstrak. Tujuan umum pengabdian kepada masyarakat dengan Penyuluhan Kesehatan tentang Kesehatan Jiwa Usia Muda (Remaja) pendekatan Keluarga dan Agama ini sebagai Psychosocial Trauma adalah untuk meningkatkan upaya promotif guna menstimulus terciptanya sehat jiwa bagi usia muda (remaja) yang berada di LPKA kelas IIB Sungai Raya dengan mengoptimalkan peran keluarga dan basis agama, diharapkan dapat terbentuknya karakteristik anak didik usia muda yang selalu memiliki keyakinan agama yang kuat dalam 
berpikir dan bertindak, berpositif thingking, mengaktualisasikan kemampuan diri secara baik, dan memiliki pandangan hidup kedepan yang lebih baik. Metode PKM ini adalah menggunakan teknik ceramah dan diskusi. Sasaran kegiatan ini adalah anak didik usia muda (remaja) yang mendiami LPKA kelas IIB Sungai Raya Kabupaten Pontianak. Tim pelaksana PKM adalah Dosen dengan melibatkan tenaga kependidikan serta Mahasiswa STIK Muhammadiyah Pontianak. Hasil pelaksanaan PKM menunjukkan antusiasme peserta aktif karena tema penkes belum pernah diketahui oleh anak didik di LPKA kelas IIB Sungai Raya dan kegiatan berlangsung tertib. Dari 25 peserta penkes, $80 \%$ peserta dapat menjawab dengan benar dari 5 pertanyaan yang diberikan saat evaluasi sumatif dilakukan.

Keywords:

Health Education;

Mental Health;

Adolesecents.
Coresponden author:

Email: ajeng_ners@yahoo.com

artikel dengan akses terbuka dibawah lisensi CC BY -4.0

\section{PENDAHULUAN}

Pendidikan kesehatan adalah semua kegiatan untuk memberikan dan meningkatkan pengetahuan, sikap, praktik baik individu, kelompok atau masyarakat dalam memelihara dan meningkatkan kesehatan mereka sendiri (Notoatmodjo, 2012). Hasil penelitian Lubis, Namora, dan Eddy (2013) menunjukkan bahwa terdapat peningkatan pengetahuan dan sikap pada responden akibat dari intervensi melalui penyuluhan dengan metode ceramah, terdapat peningkatan pengetahuan dan sikap pada responden akibat dari intervensi melalui penyuluhan dengan metode diskusi. Metode penyuluhan yang paling efektif digunakan untuk meningkatkan pengetahuan dan sikap anak sekolah dasar tentang PHBS adalah melalui metode diskusi. Penyuluhan dengan metode ceramah dapat meningkatkan pengetahuan. Sejalan dengan Green dalam Tampubolon (2009) dalam Notoadmojo (2012) bahwa dengan pendekatan edukasional dapat merubah perilaku seseorang termasuk pengetahuan, dimana intervensi yang diberikan merupakan proses pendidikan kesehatan untuk merubah perilaku.

Ceramah merupakan metode penyuluhan kesehatan yang efektif apabila penceramah atau narasumber sendiri dapat menguasai materi, memiliki penampilan yang meyakinkan serta mampu mempersiapkan alat-alat bantu pengajaran misalnya makalah singkat, slide, sound system dan sebagainya (Mubarak, dkk., 2007). Kelebihan metode ceramah sebagai berikut: 1) Dapat menampung kelas besar dimana tiap siswa mempunyai kesempatan yang sama untuk mendengarkan dan biaya yang diperlukan relative murah; 2) Konsep yang disajikan secara hierarki akan memberikan fasilitas belajar pada siswa; 3) Guru dapat memberikan tekanan terhadapat hal-hal penting hingga waktu dan energi dapat digunakan sebaik mungkin; 4) Kekurangan atau tidak adanya buku sumber dan alat bantu pelajaran tidak menghambat terlaksananya proses pembelajaran (Melvin, 1996 dalam Saroh, 2015).

LPKA kelas IIB Sungai Raya dihuni oleh anak-anak usia muda. Kepala LPKA kelas IIB Sungai Raya mendukung adanya upaya-upaya pengembangan pendidikan untuk meningkatkan pengetahuan pada anak-anak binaannya. Kabupaten Kubu Raya juga dicanangkan menjadi salah satu Kabupaten Layak Anak sehingga perhatian, pengembangan dan dukungan setiap program yang ada di Lembaga Pembinaan Khusus Anak Kelas IIB Sungai Raya. Belum optimalnya perhatian pihak pemerintah daerah ataupun lembaga lainnya untuk peningkatan kualitas pendidikan khususnya bidang kesehatan di LPKA kelas IIB Sungai Raya, pengetahuan tentang sehat jiwa bagi anak-anak usia muda masih rendah, dan penyuluhan kesehatan tentang kesehatan jiwa usia muda belum pernah dilakukan di LPKA kelas IIB Sungai Raya.

Hasil Riset Kesehatan Dasar Balai Penelitian dan Pengembangan Kesehatan (2013) menunjukkan angka prevalensi gangguan jiwa berat di Indonesia 1.7 permil, artinya ada 
sekitar 1.7 kasus gangguan jiwa berat di antara 1000 orang penduduk Indonesia. Gangguan jiwa berat adalah gangguan jiwa yang ditandai dengan terganggunya kemampuan menilai realitas dan tilikan diri (insight) yang buruk. Gejala yang menyertai gangguan ini antara lain berupa halusinasi, wahan, gangguan proses pikir dan kemampuan berpikir, dan tingkah laku aneh seperti katatonik. Gangguan mental emosional dapat dialami oleh semua orang dan setiap tingkatan usia pada kondisi distres psikologis, namun tetap dapat pulih seperti semula. Orang Dengan Masalah Kejiwaan (ODMK), jika tidak mendapatkan intervensi dari profesional kesehatan mental dengan tepat, maka orang dengan gangguan mental emosional dapat mengalami gangguan yang lebih serius (Kurniawan dan Indahria, 2016).

PKM ini sejalan dengan Program Indonesia Sehat (PSI-PK) yang merupakan salah satu program dari Agenda ke-5 Nawa Cita, yaitu Meningkatkan Kualitas Hidup Manusia Indonesia. Program ini didukung oleh program sektoral lainnya yaitu Program Indonesia Pintar, Program Indonesia Kerja, dan Program Indonesia Sejahtera. Dampak akibat gangguan mental yang serius adalah kematian atau bunuh diri. Kisaran usia tertinggi akibat bunuh diri adalah usia $15-29$ tahun (WHO, 2015). Gangguan jiwa sangat lazim terjadi pada remaja-remaja dengan perilaku bunuh diri. Tidak semua tindakan bunuh diri disebabkan oleh gangguan jiwa, tetapi $80-90 \%$ remaja yang meninggal karena bunuh diri mempunyai psikopatologi signifikan seperti gangguan mood, gangguan cemas, problem perilaku, dan penyalahgunaan NAPZA (Yusuf, 2019). Kasus terbesar pada anak didik di LPKA kelas IIB Sungai Raya adalah $80 \%$ dengan kasus asusila dan $20 \%$ dengan kasus narkoba. Hal ini tentu menjadi stressor bagi anak usia muda (remaja) yang mengalami kasus kriminal akibat penyimpangan perilaku pada remaja. Mereka harus mengalami perubahan lingkungan tempat tinggal dan orang-orang disekitarnya yang awalnya bersama keluarga ke LPKA. Kesehatan mental bagi anak usia dini memerlukan perhatian penting agar pergeseran rentang sehat sakit dapat dicegah sehingga kualitas hidup remaja khusunya di LPKA dapat ditingkatkan.

\section{Metode}

Pendekatan yang ditawarkan dalam pengabdian kepada masyarakat ini adalah dengan melakukan penyuluhan kesehatan dengan metode ceramah dan diskusi tentang sehat jiwa usia muda (remaja) pendekatan keluarga dan agama sebagai psychosocial trauma di LPKA kelas IIB Sungai Raya, Kabupaten Kubu Raya, Kalimantan Barat. Pelaksanaan pengabdian kepada masyarakat ini meliputi tahapan sebagai berikut: 1) Penyusunan proposal pengabdian kepada masyarakat ini pada mitra, sesuai dengan permasalahan yang telah disampaikan pada pihak pengusul kegiatan dan jadwal pelaksanaan kegiatan ini bersama mitra, 2) Persiapan surat untuk pelaksanaan kegiatan dan media yang diperlukan selama kegiatan pengabdian kepada masyarakat ini selenggarakan seperti power point/handout dan form absensi, 3) Berkolaborasi dengan pihak mitra untuk penyediaan tempat dan fasilitas penunjang seperti pengeras suara, LCD, kursi dan meja, 4) Implementasi kegiatan pengabdian kepada masyarakat ini dengan 3 tahapan yaitu tahap pembukaan, tahap isi/penyampaian materi, dan tahap penutup, 5) Penyusunan hasil penyuluhan kesehatan untuk publikasi jurnal dan media online.

\section{Hasil Dan Pembahasan}

Pelaksanaan pengabdian kepada masyarakat ini ditentukan berdasarkan hasil studi awal yang telah dilakukan pengusul dengan data dasar yang didapatkan bahwa di LPKA kelas IIB Sungai Raya belum pernah dilakukan penyuluhan kesehatan dengan tema ini dan terindikasi adanya perubahan sikap dan perilaku anak-anak disana. PKM ini dilakukan sebanyak satu kali pertemuan. Pelaksaan PKM ini dilakukan pada tanggal 28 Juni 2019, hari jumat, dimulai dari pukul 09.00 WIB sampai 11.05.00 WIB. Kegiatan penyuluhan kesehatan ditempatkan pada aula pertemuan LPKA kelas IIB Sungai Raya. Jumlah peserta dalam PKM ini sebanyak 25 anak remaja mulai dari rentang usia 10-25 tahun.

Berikut dokumentasi dalam PKM ini: 


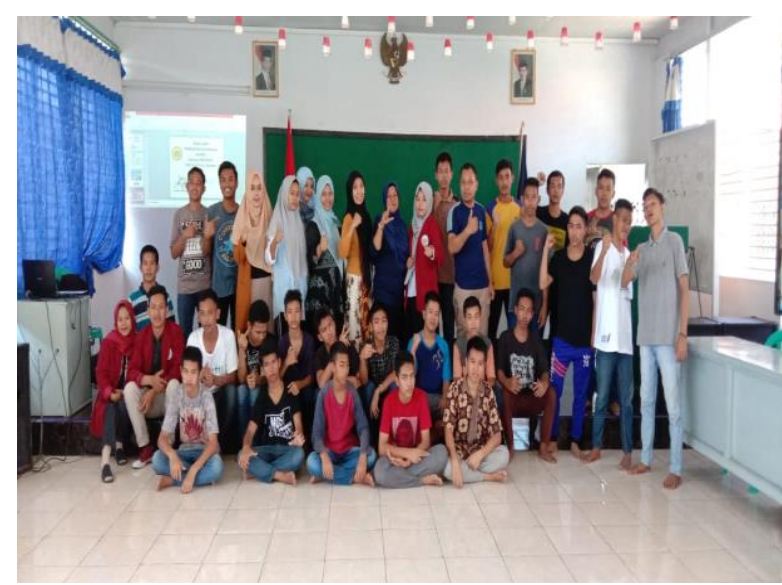

Gambar 1 Peserta \& Panitia PKM yang hadir

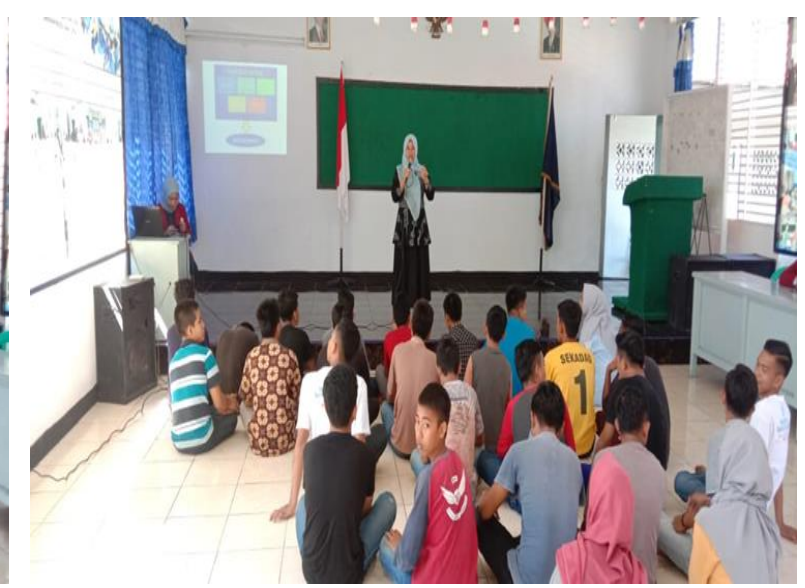

Gambar 2 Penyampaian Materi Penkes

Kegiatan penkes diawali pembukaan oleh pihak pemegang program Penyakit Tidak Menular (PTM) Puskesmas Sungai Raya Dalam. Pihak LPKA kelas IIB Sungai Raya di hadiri oleh petugas kesehatan LPKA didampingi oleh beberapa orang bagian keamanan LPKA dan staf lainnya yang secara antusias ingin melihat dan mendengarkan isi penyuluhan kesehatan ini dikarenakan tema ini belum pernah diberikan di LPKA kelas IIB Sungai Raya. Pihak LPKA tersebut sangat mengapresiasi kegiatan penyuluhan kesehatan ini bahkan diharapkan kedepannya perlu adanya kerjasama / MoU yang dapat memberikan support dalam optimalisasi program-program lainnya sejalan dengan kebutuhan anak didik maupun petugas/staf yang ada di LPKA kelas IIB Sungai Raya guna menghasilkan raw input dan raw output yang sesuai dengan capaian target program serta capaian kualitas hidup masyarakat berdasarkan tingkatan usia.

Penyuluhan kesehatan ini dilakukan dengan metode ceramah dan diskusi, tujuannya agar melalui penyampaian informasi dengan tema pertama kali ini diberikan mampu memberikan pengetahuan bagi anak-anak (sasaran utama) dan seluruh petugas yang berada di LPKA kelas IIB Sungai Raya. Peran keluarga dan agama sangatlah penting bagi terciptanya jiwa individu yang sehat, mengingat bahwa yang berada di LPKA ini adalah anak usia remaja yang merupakan bagian dari penerus bangsa, sehingga sangat penting untuk mereka (remaja) yang sudah terlanjur memiliki pengalaman dengan pelanggaran hukum seperti asusila dan narkoba dapat memiliki kesadaran untuk membentuk jiwa atau karater diri menjadi positif.

Pendekatan keluarga dan agama merupakan garda terdepan dalam menstimulus sikap dan perilaku anak usia remaja yang berada di LPKA tersebut untuk mengisi hari-hari selama menjalani proses hukum dengan optimis mampu memperbaiki diri agar tidak mengulang, memiliki cita dan harapan kedepan yang lebih baik. Kasih sayang, perhatian, dan support system dari keluarga serta pendekatan ikhtiar melalui agama yang dianut remaja di LPKA tersebut sangat berarti.

Materi disampaikan memakan waktu \pm 60 menit yang dilanjutkan dengan diskusi. Pada saat diskusi ada 4 orang audience (remaja) yang bertanya sesuai dengan tema penyuluhan kesehatan yang telah disampaikan. Semua pertanyaan dapat dijawab dengan baik oleh pemberi materi dan narasumber lainnya yang merupakan bagian dari tim pengusul PKM ini. Sesi evaluasi, pemateri meminta 3 orang audience untuk menjelaskan kembali sesuai hasil tahu dari isi materi penkes yang telah diberikan. Ketiga audience tersebut mampu menjawab dengan baik dan sesuai dengan isi materi yang telah diberikan.

Tahap kesimpulan pemateri menyimpulkan isi penkes dan memberikan reinforcement bagi remaja agar mampu menumbuhkan rasa percaya diri untuk mampu bersosialisasi dilingkungan luar LPKA, percaya diri dan yakin akan kemampuan positif yang dimilikinya, optimis dalam menjalani kehidupan dengan sebaik-baiknya, berikhtiar untuk tidak terjerumus ke pengalaman yang tidak baik, yakin bahwa keluarga sangat sayang dan selalu ingin mendampingi anak-anaknya tumbuh menjadi anak yang baik, serta yang paling mendasar adalah rasa bersyukur bahwa Allah SWT senantiasa ada memberi ridho untuk setiap hambaNya yang ingin bertaubat. 
Setiap tahapan dari awal kegiatan belajar mengajar penyuluhan kesehatan ini diberikan pemberian reward yang sesuai hingga tahap penutup sebagai bentuk bina hubungan saling percaya (BHSP) dan support system selama penkes ini diselenggarakan.

Akhir penyuluhan kesehatan ini, ada satu orang audience yang memberikan masukan bagi tim pengusul PKM ini, peserta berharap Puskesmas dan LPKA kegiatan dengan tema ini dapat ditingkatkan seperti melalui konseling atau kegiatan lainnya yang dapat membentuk karakter mereka disana bertambah kuat untuk memperbaiki diri dan optimis untuk menjadi baik bagi diri sendiri, orang lain, dan lingkungan saat mereka kembali nanti.

\section{Simpulan Dan Saran}

Kegiatan PKM tentang penyuluhan kesehatan dengan tema sehat jiwa usia muda (remaja) melalui pendekatan keluarga dan agama sebagai psychosocial trauma ini berjalan sesuai dengan perencanaan. Kegiatan PKM ini dilakukan selama satu hari atau pertemuan. Total jumlah peserta yang hadir dalam kegiatan PKM ini sebanyak 25 orang remaja. Rentang usia peserta kegiatan di LPKA kelas IIB Sungai Raya 15-20 tahun. Kegiatan PKM tentang penyuluhan kesehatan ini menggunakan metode ceramah dan diskusi. Antusiasme peserta aktif dan kegiatan berlangsung tertib. Tahapan penyuluhan kesehatan ini dilakukan dengan 3 tahapan yaitu tahap pembukaan, kerja dan penutup. Pada saat tahap kerja setelah penyampaian materi penkes, selanjutnya tahap diskusi dilakukan dan ada satu orang peserta yang bertanya sesuai tema penkes. Dua puluh lima peserta penkes, $80 \%$ peserta dapat menjawab dengan benar dari 5 pertanyaan yang diberikan saat evaluasi sumatif dilakukan. Media yang digunakan saat PKM ini pengeras suara, LCD dan Power Point Slide. Pelaksanaan PKM ini melibatkan mitra yaitu Pihak Puskesmas Sungai Raya Dalam melalui pemegang program berkoordinasi dan LPKA bagian Pembinaan dan Petugas Kesehatan di LPKA kelas IIB Sungai Raya.

Saran yang ditujukan untuk anak didik di LPKA kelas IIB Sungai Raya yaitu diharapkan seluruh anak didik di LPKA kelas IIB terlibat aktif dalam setiap kegiatan atau program-program yang sudah terjadwal oleh LPKA guna meningkatkan kemampuan kognitif, afektif dan psikomotor remaja khusunya terkait dengan kesehatan jiwa remaja dengan melibatkan peran keluarga dan agama. Bagi LPKA kelas IIB Sungai Raya yaitu dapat meningkatkan fasilitas dan pengembangan program-program khususnya terkait kesehatan jiwa untuk remaja penghuni LPKA serta guna meminimalisasi dampak psychosocial truma bagi remaja penghuni LPKA kelas IIB Sungai Raya. Bagi institusi pengusul PKM dapat meningkatkan kerjasama lintas sektoral dan lintas program guna mencapai status kesehatan individu khususnya remaja di LPKA dalam bentuk MoU untuk pelaksanaan Tridharma Perguruan Tinggi.

\section{Daftar Rujukan}

Ardila, Aris, Abduh Ridha, dan Abdul Haris J. (2014). Efektifitas metode diskusi kelompok dan metode ceramah terhadap peningkatan pengetahuan dan sikap remaja tentang perilaku seks pranikah (Study Kasus Remaja Kelas X Ipa Di Sma Negeri 01 Bengkayang). http://openjurnal.unmuhpnk.ac.id/index.php/JJUM/article/viewFile/321/256. Diakses tanggal 17 Oktober 2018.

Depkes RI. (2010). http://www.depkes.go.id/article/view/17070700004/program-indonesiasehat-dengan-pendekatan-keluarga.htmlKepmenkes $\quad$ RI Nomor 908/Menkes/SK/VII/2010. Diakses tanggal 10 Oktober 2018.

Kepmenkes RI. 2010. http://kesmas.kemkes.go.id/perpu/konten/kmk/keputusan-menterikesehatan-nomor-908-tahun-2010. Diakses tanggal 15 Oktober 2018.

Kurniawan \& Indahria. (2016). Komunitas SEHATI (Sehat Jiwa dan Hati) sebagai intervensi kesehatan mental berbasis masyarakat. Jurnal Psikologi dan Kesehatan Mental, pISSN 2528-0104 | e-ISSN 2528-5181. https://media.neliti.com/media/publications/70507-IDkomunitas-sehati-sehat-jiwa-dan-hati-seb.pdf. Diakses tanggal 10 Juni 2019. 
95| Celebes Abdimas: Jurnal Pengabdian Kepada Masyarakat

Lubis, Namora, dan Eddy. 2013. Pengaruh penyuluhan dengan metode ceramah dan diskusi terhadap peningkatan pengetahuan dan sikap anak tentang phbs di Sekolah Dasar Negeri 065014 Kelurahan Namogajah Kecamatan Medan Tuntungan. file://C:/Users/User/Downloads/Documents/14398-ID-pengaruh-penyuluhan-

dengan-metode-ceramah-dan-diskusi-terhadap-peningkatan-penge.pdf. Diakses tanggal 17 Oktober 2018.

Mubarak, dkk. 2007. Promosi kesehatan: sebuah pengantar pendidikan. Yogyakarta: Graha Ilmu. Notoadmodjo. 2012. Promosi kesehatan dan perilaku kekerasan. Jakarta: Rineka Cipta.

Saroh. (2015). Pelaksaanaa metode ceramah dan diskusi kelompok dalam meningkatkan efektifitas pembelajaran pendidikan agama Islam di Sekolah Rungrote Wittaya Songkhla, Thailand. file:///C:/Users/User/Downloads/Documents/10110278.pdf. Diakses tanggal 10 juni 2019.

Yusuf. (2019). Upaya penurunan prevalensi ODMK dan ODGJ. file://C:/Users/User/Downloads/Documents/2-Upaya-Penurunan-Prevalensi-ODGJdan-ODMK.pdf. Diakses tanggal 15 Oktober 2018.

Yusuf. 2017. https://www.pontianakpost.co.id/lpka-minim-perhatian-pemkab. Diakses tanggal 15 Oktober 2018. 